\title{
A pedagogia libertadora e a práxis educativa freireana na Educação Profissional e Tecnológica: o caso do curso técnico em Vigilância em Saúde integrado ao Ensino Médio
}

Hellen Vivian Moreira dos Anjos ${ }^{1}$, Giuliana de Sá Ferreira Barros ${ }^{2}$, Fernando Barreto Rodrigues ${ }^{3}$

\section{Resumo}

Este artigo traz a experiência da prática libertadora freireana na concepção do projeto do curso técnico em Vigilância em Saúde integrado ao Ensino Médio, no Instituto Federal de Educação, Ciência e Tecnologia do Norte de Minas Gerais, Campus Avançado Janaúba. O objetivo é relatar como a prática pedagógica em Paulo Freire é também práxis educativa, uma vez que, mediada pela história, busca a unidade entre o ser humano e o mundo do qual ele faz parte. Resgatar a ideia da prática pedagógica freireana relacionada ao conceito de práxis e, em consequência, à Educação Profissional integrada ao Ensino Médio, faz-se imperioso, especialmente nesse contexto em que a negação da condição humana, ou da humanidade, está cada vez mais evidente. A discussão do conceito de práxis foi ancorada em Marx (2002), Losurdo (2015), Vásquez (2011), Manacorda (1996), Semeraro (2005) e, principalmente, Gramsci (1975) e Freire (1987). Em um segundo momento, foi apresentada a experiência pedagógica libertadora freireana no curso técnico em Vigilância em Saúde no Instituto. Por fim, discorreu-se sobre os princípios metodológicos e organizacionais do curso, dando ênfase à sua estrutura curricular baseada na metodologia dos temas geradores.

\section{Palavras-chave}

Paulo Freire. Práxis pedagógica freireana. Pedagogia libertadora. Ensino médio integrado. Educação profissional.

\footnotetext{
1 Doutoranda em Desenvolvimento Social pela Universidade Estadual de Montes Claros, Minas Gerais, Brasil; professora efetiva do Instituto Federal de Educação, Ciência e Tecnologia Norte de Minas Gerais, Campus Avançado Janaúba, Minas Gerais, Brasil. E-mail: hellen.anjos@ifnmg.edu.br.

2 Doutora em Educação pela Universidade Federal de Minas Gerais, Brasi; professora efetiva no Instituto Federal de Educação, Ciência e Tecnologia do Norte de Minas Gerais, Campus Avançado Salinas, Minas Gerais, Brasil. E-mail: giuliana.sa@ifnmg.edu.br.

${ }^{3}$ Doutor em Zootecnia pela Universidade Estadual do Sudoeste da Bahia, Brasil; professor efetivo do Instituto Federal de Educação, Ciência e Tecnologia do Norte de Minas Gerais, Campus Avançado Janaúba, Minas Gerais, Brasil. E-mail: fernando.barreto@ifnmg.edu.br.
} 


\begin{abstract}
Liberating pedagogy and freirean educational praxis in Professional and Technological Education: the case of the Technical Course in Health Surveillance integrated to High School Education
\end{abstract}

Hellen Vivian Moreira dos Anjos ${ }^{4}$, Giuliana de Sá Ferreira Barros ${ }^{5}$, Fernando Barreto Rodrigues ${ }^{6}$

\begin{abstract}
This article brings the experience of Freire's liberating practice in the design of the project for the technical course in Health Surveillance integrated to High School Education at the Federal Institute of Education, Science and Technology from the Northern Minas Gerais, Advanced Campus Janaúba. It aims to report how the pedagogical practice in Paulo Freire is also an educational praxis, since, mediated by history, it seeks the unity between the human being and the world of which he is part. To rescue the idea of Freire's pedagogical practice related to the concept of praxis and, as a result, to Professional Education integrated to High School Education, is imperative, especially in this context, where the denial of the human condition, or humanity, is increasingly evident. The discussion about the concept of praxis was anchored in Marx (2002), Losurdo (2015), Vásquez (2011), Manacorda (1996), Semeraro (2005) and, mainly, in Gramsci (1975) and Freire (1987). In a second moment, it was presented the Freirean Pedagogical Liberating experience in the technical course in Health Surveillance at Institute. Finally, the methodological and organizational principles of the course were discussed, emphasizing its curricular structure based on the Generating Themes methodology.
\end{abstract}

\title{
Keywords
}

Paulo Freire. Freirean pedagogical praxis. Liberating pedagogy. Integrated High School Education. Professional Education.

\footnotetext{
${ }^{4} \mathrm{PhD}$ student in Social Development, State University of Montes Claros, Minas Gerais, Brazil; effective teacher at the Federal Institute of Education, Science and Technology North of Minas Gerais, Janaúba Advanced Campus, Minas Gerais, Brazil. E-mail: hellen.anjos@ifnmg.edu.br.

${ }^{5} \mathrm{PhD}$ in Education, Federal University of Minas Gerais, Brazil; effective teacher at the Federal Institute of Education, Science and Technology of Northern Minas Gerais, Salinas Advanced Campus, Minas Gerais, Brazil. E-mail: giuliana.sa@ifnmg.edu.br.

${ }^{6} \mathrm{PhD}$ in Animal Science, State University of Southwest Bahia, Brazil; permanent professor at the Federal Institute of Education, Science and Technology of Northern Minas Gerais, Janaúba Advanced Campus, Minas Gerais, Brazil. E-mail:fernando.barreto@ifnmg.edu.br.
} 


\section{Introdução}

Neste trabalho, são propostas reflexões acerca das relações em torno do desenvolvimento da Educação Profissional e Tecnológica (EPT) a partir da práxis freireana. Trata-se de aproximar as concepções que embasam a EPT com a ideia de práxis pedagógica e da pedagogia libertadora em Paulo Freire. Compreendendo que a abordagem relacionada à educação de cunho progressista é histórica e epistemologicamente variada, além de Freire, serão trazidos para o debate autores como Marx (2002), Gramsci (1975), Vásquez (2011), Manacorda (1996), dentre outros.

As contribuições teóricas e metodológicas de Freire (1987) e de sua práxis educativa e, em consequência, dos projetos pedagógicos que nelas se apoiam, constituem-se em importantes oportunidades de pensar a educação, especialmente uma educação profissional que, como bem nos lembra Freire (1987), eleve a consciência dos sujeitos sociais sobre seu mundo imediato e os conduza à emancipação e à possibilidade da crítica e da transcendência.

Além de relatar a experiência do Instituto Federal de Educação, Ciência e Tecnologia do Norte de Minas Gerais (IFNMG), Campus Avançado Janaúba, com a sua prática pedagógica freireana baseada em temas geradores, nosso objetivo é também promover uma discussão teórica que vincule a categoria práxis à educação profissional, contribuindo, assim, para estender o debate sobre a temática à luz do marxismo. A prática pedagógica freireana é também práxis educativa, uma vez que, mediada pela história, busca a unidade entre o ser humano e o mundo do qual ele faz parte. Resgatar o conceito de práxis, ligado à ideia de Educação Profissional integrada ao Ensino Médio, faz-se imperioso, especialmente nesse contexto em que a negação da condição humana, ou da humanidade, está cada vez mais evidente.

Contudo, é impossível falar em práxis freireana e não fazer alguns questionamentos, como: o que é práxis? Qual é a perspectiva de Paulo Freire sobre práxis? Quais são as implicações dessa proposta para a Educação Profissional e Tecnológica? Uma discussão mais aprofundada sobre essas questões, ancorada nos autores que escolhemos para dialogar, pode contribuir para compreendermos melhor a ideia de uma Educação Libertadora para os oprimidos em sociedades desiguais. 


\section{O que é práxis?}

Antes de empreender esforços para a compreensão da práxis freireana, é imprescindível conhecer e interpretar o seu sentido no contexto da filosofia.

O conceito de práxis vem de uma palavra que era utilizada na antiguidade grega como sinônimo de prática (ação). Losurdo (2015) destaca que a adaptação da teoria à práxis foi tardia, parcial e contraditória, já que foram enormes os estragos provocados pelo idealismo histórico (e pelo messianismo), o que fez perder de vista a espessura ontológica das realidades e individualidades. Para Vásquez (2011), a práxis ocupa lugar central como elemento de interpretação do mundo e também como elemento do processo de sua transformação.

Segundo Gramsci (1975), seria necessário conceber o homem como uma série de relações ativas em que a individualidade se faz importante. Para ele, o indivíduo não se relaciona com outros homens por justaposição, mas organicamente. Assim, o homem não entra em relacionamento com a natureza por ser, ele próprio, natureza, mas ativamente, por meio do trabalho e da técnica.

Vásquez (2011) nos lembra, ainda, que Gramsci também sinaliza práxis como ponto fundamental para a ação transformadora dos homens no mundo. Ao surgir na vanguarda do movimento marxista, Gramsci desenvolve um significado mais amplo para o conceito de práxis a partir da interlocução com a concepção de Marx.

Konder (2018) enfatiza que, para Gramsci, a autotransformação do marxismo só poderia ser concebida ao ter em vista a práxis como centro do processo de reflexão. A práxis apresentada pelo filósofo sardo coloca a história como ponto central. O entendimento de práxis para Gramsci continua com o foco na atividade humana, entretanto, ele acrescenta a história como elemento novo, intrínseco à vida humana, e eleva a práxis ao princípio unificador e à categoria filosófica central. A práxis é, para ele, a categoria central, porque considera o que existe como resultado da ação transformadora dos homens.

A análise que envolve as questões inerentes à relação entre sujeito e objeto, espírito e matéria, ação de massa e ato histórico, constitui importante eixo para a construção do conceito de práxis para Gramsci. O entendimento de que filosofia e história são conectadas ao real é significativo para a base da teoria gramsciana. Gramsci (1975) evidencia que a realidade em movimento e o conceito de realidade devem ser compreendidos como unidade única, indivisível a partir do olhar da história, sendo imprescindível a distinção lógica. 
A questão de saber se o pensamento humano pertence à verdade objetiva não é, para Marx (2002), uma questão teórica, mas uma questão prática. É na práxis que o ser humano tem de comprovar a verdade, isto é, a realidade e o poder, o caráter terreno do seu pensamento. A disputa sobre a realidade ou não realidade de um pensamento que se isola da práxis é uma questão puramente escolástica.

Ao entender o trabalho como práxis, Marx já havia posto em evidência que a unidade de teoria e prática se concretiza na relação entre ciência e indústria, na integração do ensino com processo produtivo (MANACORDA, 1996). Sem descuidar dos fatores econômicos e da "base estrutural”, Gramsci aprofunda a visão de Marx, mas imprime a própria peculiaridade, porque enfatiza os nexos dialéticos entre estrutura e superestrutura e dedica-se a analisar o Trabalho também como parte integrante da esfera superestrutural, como componente essencial do processo educativo. Para Semeraro (2005), Gramsci coloca na base da formação humana e da escola, o conceito do equilíbrio entre ordem social e ordem natural sobre o fundamento do Trabalho, da atividade teórico-prática do homem.

Tendo em vista as perspectivas de Marx e Gramsci de que trabalho e práxis estão intimamente ligados, compreendemos, ainda amparados em Semeraro (2005), que Gramsci, ao apresentar estudos sobre a concepção de Trabalho, esquadrinha o entendimento sobre teoria e prática em Marx, enfatizando os "nexos dialéticos” entre estrutura e superestrutura. Dessa forma, é possível destacar que esse é o elo que liga Marx, Gramsci e Paulo Freire - a práxis como movimento orgânico em prol da emancipação popular. Essa perspectiva nos permite estudar a Educação Profissional e Tecnológica na sua gênese.

Retomar a gênese do conceito de práxis é essencial para a compreensão dessa categoria em Paulo Freire e como ela se relaciona com a Educação Profissional e Tecnológica. A nossa intenção não é somente estudar um referencial teórico, mas compreender como essas reflexões podem contribuir para a EPT e para os estudos sobre trabalho. No livro Pedagogia da Autonomia (1996, p. 16-22), ao enfatizar que "ensinar exige respeito aos saberes dos educandos" e "ensinar exige reflexão crítica sobre a prática", Freire (1996) aponta princípios do conceito de práxis aplicados à Educação. Outro exemplo está no livro Política e Educação (1987), no qual Freire explica que:

Como processo de conhecimento, formação política, manifestação ética, procura da boniteza, capacitação científica e técnica, a Educação é prática indispensável aos seres humanos e deles específica na História como movimento, como luta. A História como possibilidade não prescinde da 
controvérsia, dos conflitos que, em si mesmos, já engendrariam a necessidade da Educação. (FREIRE, 1987, p. 10).

Se somos sujeitos históricos, o nosso pensamento, ação e reflexão correspondem a uma tríade e estão permeados pela história. Para Freire (1987), os sujeitos se fazem na palavra, no trabalho e na ação-reflexão. Sujeitos que, em um movimento dialético, devem investigar seu atuar sobre a realidade, que é a sua práxis. Esse é um movimento que faz parte da atividade humana em todo seu percurso histórico. É práxis. É a práxis freireana.

\section{A experiência pedagógica libertadora freireana no curso técnico em Vigilância em Saúde integrado ao Ensino Médio no IFNMG, Campus Avançado Janaúba}

A ideia da concepção do Projeto Político Pedagógico para o curso técnico em Vigilância em Saúde integrado ao Ensino Médio foi gestada a partir das discussões geradas no $1^{\circ}$ Seminário em Integração Curricular realizado pelo Campus Avançado Janaúba no ano de 2016. Nesse seminário, as discussões giraram em torno do desejo que os servidores do campus, recém-inaugurado, tinham em conceber uma educação que considerasse o contexto no qual a instituição está inserida: o extremo norte do Estado de Minas Gerais, mais especificamente, no território da Serra Geral, região a qual engloba dezesseis municípios e que tem a cidade de Janaúba como polo.

A pedagogia libertadora freireana visa à emancipação dos oprimidos e era justamente isso que almejávamos perseguir. Nada mais apropriado para uma região oprimida e alijada de oportunidades de todas as ordens do que uma formação que vise à libertação de todos os grilhões socioeducacionais que, historicamente, interromperam o sonho dos filhos da classe trabalhadora.

Buscávamos construir um projeto para um curso técnico integrado ao Ensino Médio, ou seja, interessava-nos a busca de relações com as problemáticas reais do cotidiano dos estudantes. Mas, qual realidade era essa e quais as características dos sujeitos que acessariam tal curso? Era preciso levar em conta o contexto no qual o IFNMG, Campus Avançado Janaúba estava inserido.

O território da cidadania da Serra Geral, segundo Noce e Neto (2015), possui uma área total de $20.581,20 \mathrm{~km}^{2}$, cujas condições climáticas são predominantemente do tipo semiárido. O índice de pobreza, que representa o percentual de habitantes considerados pobres na região, chega a 54\% pela média dos municípios, muito acima do índice do país, que está abaixo de 
30\%. Já a média dos municípios para o índice de Gini, coeficiente utilizado para determinar o grau de desigualdade entre as camadas da população, está em 0,39 , bem abaixo da média nacional, próxima de 0,6 . Tais dados indicam que a desigualdade social não é o principal problema da região, homogeneizada pela pobreza. Com relação ao índice de desenvolvimento humano (IDH) - 0,63 pela média dos municípios, apesar de melhora substancial nos últimos 20 anos -, continua baixo, inferior à média nacional, que está acima de 0,75.

A partir desse contexto, e entusiasmados em construir uma nova proposta, que fosse na contramão da ideia de um currículo segmentado e disciplinar, começamos a organizar nossas ideias e a juntar nossos sonhos. Enquanto íamos ao encontro de algumas propostas e teorias, nos afastávamos de outras. Depois de muitas discussões e reflexões, vimos que não tínhamos um modelo em que nos encaixássemos a uma única concepção de educação.

Era preciso, dessa maneira, fazer uma tessitura que considerasse o que nos foi simpático de tudo o que conhecemos. Em A Moça Tecelã, de Marina Colasanti (2004), pelas cores das linhas a moça tece a vida e seus humores. É feliz em seu ofício e tece tudo que sua imaginação lhe permite. Assim fomos nós: tecendo um sonho de um currículo que nos representasse. E fizemos isso a muitas mãos. Etimologicamente a palavra tecido surgiu na língua portuguesa a partir do latim textus, derivado a partir de texere, que significa tecer ou entrelaçar algo com fios. Essa mesma raiz etimológica deu origem ao termo texto. Se texto é tudo aquilo que faz sentido, era preciso que esse novo currículo fizesse sentido para nós. Era verdadeiramente um desafio tudo aquilo.

Todavia, depois de tantos encontros de ideias e sugestões, nos questionamos: - Como seria o nosso novo currículo? O que sabíamos é que não era mais possível permanecer como estávamos. Não que o que tínhamos realizado até ali não fosse exitoso, ao contrário, foi. Repensamos as nossas práticas; aproveitamos os nossos acertos; refletimos sobre as nossas limitações e depreendemos que era preciso avançar em direção a uma proposta curricular de Ensino Médio Integrado que tivesse como base a educação unitária, politécnica, omnilateral e, sobretudo, libertadora. Como pode ser observado, esse exercício vai ao encontro do pensamento gramsciano em que "a identificação das palavras e sua conceituação devem ser efetuadas levando em conta o contexto cultural e histórico" (GRAMSCI, 1975, p. 1.545), o que fortalece a perspectiva orgânica do processo pedagógico, especialmente quanto à indissociabilidade entre escola e a vida dos sujeitos.

Ramos (2008) afirma que a realidade nos propõe pensar sobre o tipo de sociedade que visamos quando educamos. Visamos a uma sociedade que exclui, discrimina, fragmenta os 
sujeitos e nega direitos ou visamos a uma sociedade que inclui, que reconhece a diversidade, que valoriza os sujeitos e sua capacidade de produção da vida, assegurando direitos sociais plenos? A sua resposta aponta em direção àquilo que buscamos com esta proposta: "Nós nos colocamos na segunda posição que, em síntese, persegue a construção de uma sociedade justa e integradora" (RAMOS, 2008, p. 1). Foi nesse contexto que nos certificamos que tudo o que estávamos construindo naquele momento nos apontava para a pedagogia libertadora de Paulo Freire. Era preciso um currículo que nos libertasse de todas as nossas amarras. Sim, que libertasse a nós, servidores, e aos nossos discentes e, em consequência, a nossa comunidade.

Paulo Freire (1992) dizia que, enquanto muitas pessoas fazem discursos pragmáticos, defendem nossa adaptação aos fatos e acusam sonho e utopia, não apenas de inúteis, mas também de inoportunos, toda prática educativa progressista precisa ser desocultadora dessas mentiras dominantes. Para ele, a prática educativa de opção progressista jamais deixará de ser uma aventura desveladora, uma experiência de desocultação da verdade. Ancorados em Freire e em sua Pedagogia da Esperança, esse pequeno grupo de profissionais, inicialmente, não mais que dez, mostrou-se esperançoso não por pura teimosia, mas por um imperativo existencial e histórico. Assim deveria ser toda ação educativa destinada aos oprimidos de sociedades desiguais.

Desse modo, a escola que compreendemos ser necessária está em construção. Nosso maior interesse é transpor a presença dessa escola em que acreditamos na sociedade, ao saber que ela se destina à promoção do homem e à sua compreensão no seu estar no mundo.

\section{Sobre o curso técnico em Vigilância em Saúde integrado ao Ensino Médio}

A Constituição Federal de 1988, em seu artigo 205, reconhece a educação como direito fundamental compartilhado entre Estado, família e sociedade, e determina que "a educação, direito de todos e dever do Estado e da família, seja promovida e incentivada com a colaboração da sociedade, visando ao pleno desenvolvimento da pessoa, seu preparo para o exercício da cidadania e sua qualificação para o trabalho" (BRASIL, 1988).

Tomando esse direito público subjetivo como condição de emancipação humana, a pergunta que nos motivou na busca por outra educação foi: é possível que um currículo compartimentado em disciplinas estanques, descontextualizado dos temas que movem o mundo, seja capaz de promover o pleno desenvolvimento do sujeito? Será capaz de prepará-lo para o exercício consciente e livre de sua cidadania? Será capaz de prepará-lo para o mundo 
do trabalho em uma sociedade capitalista onde o nosso maior desafio enquanto ser trabalhador é o de superar a nossa condição de coisificação ou reificação para a condição de ser emancipado? Essas indagações nos serviram como bússolas que nos guiaram na construção da nossa proposta freireana de Ensino Médio Integrado.

Para Pacheco (2010), os Institutos Federais de Educação, Ciência e Tecnologia são a síntese daquilo que a Rede Federal construiu de melhor ao longo de sua história e das políticas de Educação Profissional e Tecnológica do governo federal. São caracterizados pela ousadia e inovação, necessárias a uma política e a um conceito que buscam antecipar, aqui e agora, as bases de uma escola contemporânea do futuro e comprometida com uma sociedade radicalmente democrática e socialmente justa.

Dessa maneira, buscou-se uma concepção de uma nova escola, amparada em um currículo inovador por temas geradores, tendo os conceitos de escola unitária, politécnica e libertadora como âncoras teórico-metodológicas. Esse pressuposto parte de um processo pedagógico que:

implica, necessariamente, uma metodologia que não pode contradizer a dialogicidade da educação libertadora. Daí que seja igualmente dialógica. Daí que, conscientizadora também, proporcione ao mesmo tempo a apreensão dos "temas geradores" e a tomada de consciência dos indivíduos em torno dos mesmos. (FREIRE, 1987, p. 87).

Nessa perspectiva, a práxis é materializada com vistas a concretizar um trabalho dialógico, especialmente no Brasil, um país caracterizado por uma acentuada diversidade cultural e profundas desigualdades sociais. Dessa forma, os sistemas e redes de ensino têm a obrigação ético-política de pensar currículos que considerem as necessidades, as possibilidades e os interesses dos discentes, assim como suas identidades linguísticas, étnicas e culturais. O grande desafio da escola é, então, construir práticas que propiciem aos discentes uma visão mais crítica do mundo que os rodeia. Essa preocupação, segundo Saviani (2007), tem sido tratada pelas tendências educacionais progressistas, das quais fazem parte as teorias Libertadora, Progressista Libertária e Crítico Social dos Conteúdos.

$\mathrm{Na}$ pedagogia libertadora é o grupo de discussão que dá condução ao processo educativo e busca os conteúdos problematizadores. A "unidade do saber" adotada por uma pedagogia dessa natureza é algo para além das disciplinas e do seu caráter compartimentado. São os temas geradores o ponto de partida para a descodificação do mundo. A ideia de tema gerador parte da ideia de "palavra geradora", explicitada por Freire (1987) em Pedagogia do 
Oprimido. Para ele, o sujeito do conhecimento já sabe que a língua também é cultura e que o homem é sujeito. Nesse método, o educando sente-se desafiado a desvelar os segredos de sua constituição, a partir da construção de suas palavras - também construção de seu mundo.

No caso do projeto para o curso técnico integrado em Vigilância em Saúde partimos do que o próprio Freire diversas vezes explicou: os temas geradores são a extensão da ideia de palavras geradoras, uma vez que a decodificação das situações significadas pelos temas

geradores agrega um leque maior de possibilidades. É no grupo de discussões que, segundo Freire (1987), serão decodificadas pelo grupo várias unidades básicas, codificações simples e sugestivas, que, dialogicamente decodifìcadas, redescobrem o homem como sujeito de todo o processo histórico da cultura e, obviamente, também da cultura letrada.

A decodificação dos temas relacionados à sua cultura, aos seus saberes, às suas vivências, dores e sabores é, certamente, o ponto de partida para a decodificação do mundo social, político, cultural, histórico e laboral dos oprimidos em sociedades capitalistas e, portanto, desiguais.

O ensino por meio dos temas geradores considera a adoção de situações que cercam a realidade dos educandos e dos educadores. É preciso fazer sentido. Quantas vezes já nos questionamos sobre o sentido de determinados conteúdos escolares para além da escola? Quando esse conhecimento nos será útil? No método freireano, esses temas precisam ser, não só apreendidos, mas refletidos, para que ocorra a tomada de consciência dos indivíduos sobre eles. Mais do que palavras, os temas são objetos de conhecimentos que deverão ser interpretados e representados pelos aprendizes.

Pacheco (2010) afirma que os nossos projetos pedagógicos têm de estar articulados, especialmente, com o conjunto de organismos governamentais ou da sociedade civil organizada, a qual estabelece uma relação dialética em que todos somos educadores e educandos. Por isso, devem afirmar práticas de transformação escolar com o objetivo de construir diferentes propostas que apontem os elementos do novo mundo possível.

\section{Princípios metodológicos e organizacionais do curso técnico em Vigilância em Saúde integrado ao Ensino Médio}

As orientações metodológicas que guiam o currículo integrador em que o curso técnico em Vigilância em Saúde integrado ao Ensino Médio está amparado, baseiam-se na ideia de Ramos (2007) de que a forma integrada de oferta do Ensino Médio com a Educação 
Profissional obedece a algumas diretrizes ético-políticas, a saber: integração de conhecimentos gerais e específicos; construção do conhecimento pela mediação do trabalho, da ciência e da cultura; e a utopia de superar a dominação dos trabalhadores e construir a emancipação - formação de dirigentes.

Sob esses princípios, é importante compreender que o Ensino Médio é, para Ramos (2007), a etapa da Educação Básica em que a relação entre ciência e práticas produtivas se evidencia; é a etapa biopsicológica e social de seus discentes em que ocorre o planejamento e a necessidade de inserção no mundo do trabalho, no mundo adulto. Disso decorre o compromisso com a necessidade de jovens e adultos terem a formação profissional mediada pelo conhecimento. Para o alargamento da compreensão dessa nova escola, unitária e politécnica por natureza, faz-se imperioso considerar os conceitos que são inerentes a uma perspectiva integrada de educação.

Para Kuenzer (2005), um primeiro conceito é a politecnia, que significa o domínio intelectual da técnica e a possibilidade de exercer trabalhos flexíveis, recompondo as tarefas de forma criativa; supõe a superação de um conhecimento meramente empírico e de formação apenas técnica, pelas formas de pensamento mais abstratas, de crítica, de criação, que exigem autonomia intelectual e ética. Para a autora, é mais que a soma de partes fragmentadas; supõe uma rearticulação do conhecido, o que ultrapassa a aparência dos fenômenos para compreender as relações mais íntimas, a organização peculiar das partes, descortinando novas percepções que passam a configurar uma compreensão nova e superior da totalidade, que não estava dada no ponto de partida. A politecnia cria a possibilidade de construção do novo, e permite aproximações sucessivas da verdade, que nunca se dá a conhecer plenamente; por isso, o conhecimento resulta do processo de construção da totalidade, que nunca se encerra, pois há sempre algo novo para conhecer.

O trabalho como princípio educativo, no seu sentido ontológico, segundo Ramos (2007), perfaz-se como processo inerente da formação e da realização humana. Não se trata somente da prática econômica de se ganhar a vida vendendo a força de trabalho - forma específica que se configura na sociedade capitalista. Antes, passa a ser compreendido como a ação humana de interação com a realidade para a satisfação de necessidades e produção de liberdade. Nesse sentido, trabalho não é emprego, não é ação econômica específica. Trabalho é produção, criação, realização humana.

Compreender o trabalho nessa perspectiva é compreender a história da humanidade, as suas lutas e conquistas mediadas pelo conhecimento humano. Considerar o trabalho como 
princípio educativo equivale a dizer que o ser humano é produtor de sua realidade e, por isso, se apropria dela e pode transformá-la. Equivale a dizer que nós somos sujeitos de nossa história e nossa realidade. Em síntese, o trabalho é a primeira mediação entre o homem e a realidade material e social (BRASIL, 2007).

A formação omnilateral também está ligada à integração por expressar, de acordo com Ramos (2007), uma concepção de formação humana, com base na integração de todas as dimensões da vida no processo formativo. Esse sentido da integração ainda não considera se a formação é geral ou profissionalizante. Desse modo, pode orientar tanto a Educação Básica quanto a Educação Superior. A integração possibilita a formação omnilateral dos sujeitos, pois implica a integração das dimensões fundamentais da vida que estruturam a prática social. Essas dimensões são o Trabalho, a Ciência e a Cultura. O Trabalho compreendido como realização humana inerente ao ser (sentido ontológico) e como prática econômica (sentido histórico associado ao respectivo modo de produção); a Ciência compreendida como os conhecimentos produzidos pela humanidade que possibilitam o contraditório avanço produtivo; e a Cultura, que corresponde aos valores éticos e estéticos que orientam as normas de conduta de uma sociedade.

Para que se entenda como está ocorrendo a integração da Educação Profissional ao Ensino Médio a partir dessas concepções, é preciso chegar ao chão da escola, com a compreensão que as categorias que norteiam a integração - seja a politecnia, o trabalho como princípio educativo, a formação omnilateral, a ciência e a cultura - estejam expressas no trabalho pedagógico de cada professor; não no trabalho fragmentado das disciplinas que não dialogam entre si, mas na construção de uma nova forma que supere a sobreposição de conhecimentos expressos nos conteúdos.

O Ensino Médio precisa formar amplamente os seus sujeitos a fim de fazê-los parte da sociedade. Fazer parte dessa sociedade, com dignidade, significa encontrar o caminho da realização. Por isso, urge a necessidade de se encontrar uma identidade para essa modalidade de ensino, o que poderia apontar para a construção de uma educação verdadeiramente libertadora, como tão bem defendeu Freire, capaz de responder efetivamente às demandas concretas da juventude, especialmente aquela pertencente a estratos sociais menos privilegiados.

Uma escola dessa natureza, para Ramos (2007), precisa ser politécnica, isto é, uma educação que, ao propiciar aos sujeitos o acesso aos conhecimentos e à cultura construídos pela humanidade, propicie a realização de escolhas e a construção de caminhos para a 
produção da vida. Com isso, são apresentados os dois pilares conceituais de uma educação integrada: um tipo de escola que não seja dual, ao contrário, seja unitária, garantindo a todos o direito ao conhecimento; e uma educação politécnica, que possibilite o acesso à cultura, à ciência, ao trabalho, por meio de uma Educação Básica e profissional. Ramos (2007) depreende que os estudos sobre a formação integrada evidenciam as dificuldades, mas não a impossibilidade de sua implantação, desde que apoiados por um projeto firme e coerente para sua realização. Trata-se de uma superação da mentalidade conservadora dos padrões pedagógicos vigentes, bem como de posições políticas adversas ao discurso da formação integrada e da educação emancipatória.

A Lei de Diretrizes e Bases da Educação (LDB), em seu artigo 35, inciso IV, ao propor a formação tecnológica básica como eixo do currículo, aponta a síntese entre o conhecimento geral e o específico, determinando novas formas de selecionar, organizar e tratar metodologicamente os conteúdos (KUENZER, 2005, p. 38). Essa concepção, para Ramos (2007), é correta por tomar o conceito de trabalho como práxis humana, ou seja, o conjunto de ações, materiais, espirituais, que o homem, como indivíduo e humanidade, desenvolve para transformar a natureza, a sociedade, os outros homens e a si próprio com a finalidade de produzir as condições necessárias à sua existência. Desse ponto de vista, toda e qualquer educação será educação para o trabalho.

Kuenzer (2005) defende que a escola se constituiu, historicamente, como uma das formas de materialização da divisão capitalista do trabalho entre indivíduos distintos, ou seja, como o espaço por excelência do acesso ao saber teórico, divorciado da práxis, representação abstrata feita pelo pensamento humano, e que corresponde a uma forma peculiar de sistematização elaborada a partir da cultura de uma classe social. E, não por coincidência, é a classe que detém o poder material que possui também os instrumentos materiais para a elaboração do conhecimento (MARX; ENGELS, 2001). Nessa perspectiva, Mesquida (2011, p. 34) explica que:

Para Paulo Freire, a consciência do oprimido foi moldada pela concepção de mundo do opressor. Dessa maneira, o oprimido adere aos valores, às ideologias, no sentido de falsa consciência, como as entende K. Marx na Ideologia alemã, aos interesses do opressor, fato que não lhe permite ser livre.

Ressalta-se essa confluência entre Freire e Marx tendo em vista que a escola, fruto da prática fragmentada, expressa e reproduz essa fragmentação por meio de seus conteúdos, 
métodos e formas de organização e gestão. Nesse sentido, a práxis educativa, que é a síntese da teoria e prática, vê-se esvaziada pela lógica da polarização das competências. É prática, por ser capaz de transformar a natureza, orientando a ação humana e teórica, na medida em que essa ação é consciente.

Outra teoria basilar da nossa proposta ampara-se em Ramos (2008), ao afirmar que é preciso partir da análise do processo de produção e suas múltiplas dimensões (físicoambiental, econômico-produtiva, técnico-organizacional e sócio-histórica cultural). Baseados nessa perspectiva curricular, teremos a Vigilância em Saúde como pressuposto de uma grande parte de nossos temas geradores. A partir daí, buscamos uma visão interdisciplinar e transdisciplinar do conhecimento, que aborde, de uma maneira combinada ou específica, os quatro aspectos elencados na teoria de Ramos.

Figura 1 - Esquema da interdisciplinaridade e da visão totalizante da realidade

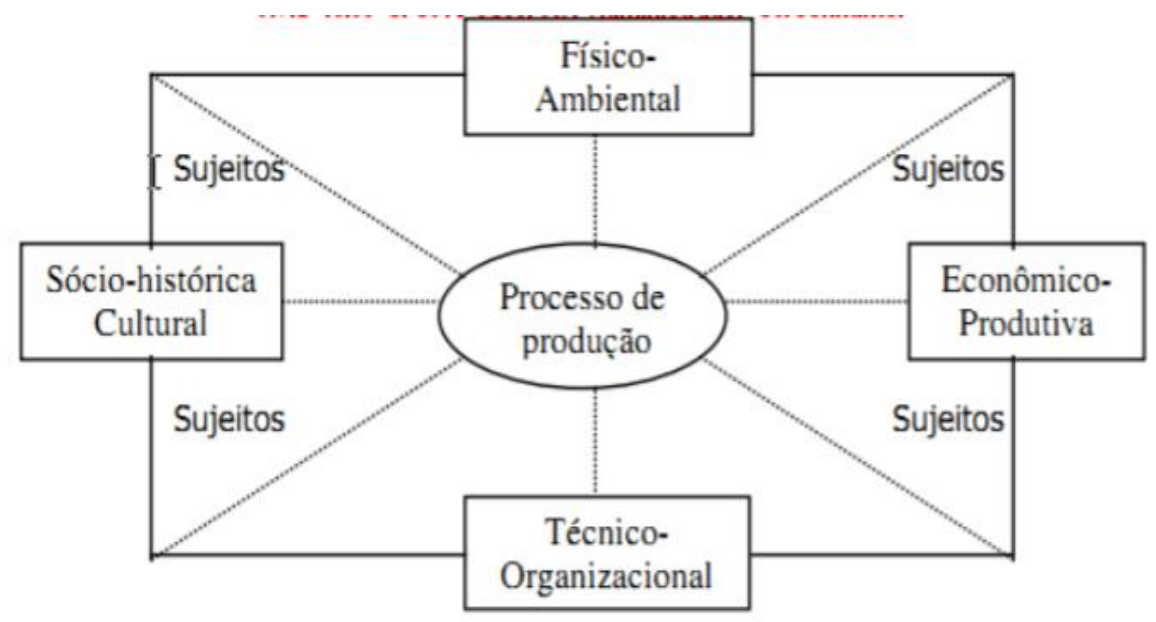

Fonte: Ramos e Ciavatta (2005).

Esse esquema, conforme Ramos e Ciavatta (2005), pressupõe outra postura epistemológica que se exige, recorrendo a princípios e pressupostos da interdisciplinaridade e da visão totalizante da realidade. Não se trata de somatório, superposição ou subordinação de conhecimentos uns aos outros, mas sim de sua integração na perspectiva da totalidade. Isso significa a superação de dicotomias entre ciência/tecnologia, entre teoria/prática; a superação da visão compartimentada de saberes; e a apropriação com maior profundidade do conhecimento, hoje em ritmo cada vez mais acelerado de construção e desconstrução.

Diante desse universo, não se pode prescindir do traçado de um novo paradigma pedagógico que ultrapasse as propostas até então ofertadas. A nossa busca é pela construção 
de uma proposta que supere o rígido limite traçado pelas disciplinas convencionais e que se construa na perspectiva da integração interdisciplinar e transdisciplinar. Além disso, é necessário fortalecer o sentimento crítico a respeito do lugar e da história que se constrói e que projeto de sociedade se pretende (BRASIL, 2021).

Pensar educação vai além de uma proposta com base em matrizes, na qual diversas vezes ainda nos vemos, de certo modo, apegados à concepção de "grades" de currículo, em uma espécie de enjaulamento dos saberes e, por que não afirmar, dos nossos discentes também. Desse modo, encontramos aqui, na proposta de trabalho com temas geradores, uma perspectiva de ensino ancorada em sua contemporaneidade: a possibilidade de transitar, fluir e esgarçar conteúdos, de modo que eles passem a constituir-se na forma de saberes - o conhecimento que não é somente do eu para o mundo e sim de diversos mundos, saberes e experiências para meu eu, em uma contramão fluida daquilo que por muito tempo concebíamos como formas de se ensinar e aprender.

Eis o nosso arcabouço: as contribuições de Freire e sua proposta por temas geradores uma constante referência ao potencial humano, no qual acreditamos como um dos elementos alicerçadores de mudanças. Onde residiam problemas e a conveniência que se aloca no espaço das realidades, do assujeitamento e da submissão, passamos a ver, analisar e contemplar aquilo que era tido como corriqueiro ou natural. Antes, aquilo que era visto como "problema" encontra-se em suas complexidades um campo de atuação e protagonismo do conhecimento, dos saberes e das práticas.

Ao ancorar-nos na perspectiva e no trabalho de Freire e na sua experiência com os temas geradores, o nosso enfoque é no caráter atitudinal, qualitativo, dentro de diferentes modos de avaliar, de forma a observar o processo de produção do nosso discente, um processo igualmente progressivo que contempla as engendras de uma formação omnilateral, dentro de uma visão de currículo que consideramos na verdadeira acepção de integrado - como concepção de formação humana; como forma de relacionar ensino e sua formação técnica e profissional, em uma espécie de equação entre as partes e o todo, que Ensino Médio e Educação Profissional formem, em uníssono, uma correlação entre as partes e a totalidade na proposta curricular. E é nessa concepção de verdadeira trilha formativa - que encontra no trabalho com os temas geradores a possibilidade de cruzar os saberes - que seguimos na busca da construção de sujeitos no mundo e para o mundo, com suas múltiplas e infinitas possibilidades de conhecer e perfazer-se continuamente. 


\section{Estrutura curricular do curso técnico em Vigilância em Saúde integrado ao Ensino}

\section{Médio}

O nosso processo educativo configura-se, em grande parte, em torno de situações reais, locais e regionais, tendo o contexto Gorutubano ${ }^{7}$ como ponto de partida e/ou ponto de chegada do nosso trabalho. Os temas geradores partem, em muitas situações, do local para o global. A proposta é dividida nas quatro grandes áreas do conhecimento, como preconiza a Base Nacional Comum Curricular - BNCC (2017): Linguagens e suas Tecnologias; Matemática e suas Tecnologias; Ciências da Natureza e suas Tecnologias; e Ciências Humanas e Sociais Aplicadas, além da Formação Técnica e Profissional. Essa divisão, em momento algum, se apresenta como segmentação do conhecimento. O currículo do curso ampara-se na ideia de um conhecimento de caráter holístico, negligenciado nas concepções positivistas e cartesianas de ensino predominantes.

O currículo do curso técnico em Vigilância em Saúde integrado ao Ensino Médio é organizado em cinco períodos por ano, com uma duração de, aproximadamente, oito semanas cada um, totalizando quinze períodos ao longo dos três anos de duração do curso.

Chamamos de tema gerador cada unidade de saber trabalhada, ideia que vai na contramão da concepção de saber compartimentado em disciplinas. Os temas geradores têm, em sua natureza, caráter interdisciplinar, popular e contextual. Para Freire (1987), o trabalho com temas geradores envolve a investigação do próprio pensar do povo. Pensar que não se dá fora dos homens, nem num homem só, nem no vazio, mas nos homens e entre os homens, e sempre referido à realidade.

Os temas geradores no currículo do curso técnico em Vigilância em Saúde integrado ao Ensino Médio são divididos em três grandes eixos e foram assim desenhados pela equipe multidisciplinar de profissionais que os conceberam:

1. Temas Geradores Essenciais Obrigatórios: dizem respeito aos temas geradores que compõem as quatro grandes áreas do conhecimento segundo a BNCC (2017) para o Ensino Médio (Linguagens e suas Tecnologias, Matemática e suas Tecnologias,

\footnotetext{
${ }^{7}$ O Vale do Gorutuba, no extremo Norte de Minas Gerais, é um território que tem como primeiros habitantes um povo cafuzo ou caboré, mescla de índios tapuias e quilombos, de negros fugidos do cativeiro e que lá se estabeleceram, tornando-se conhecidos como Gorutubanos. O quilombo do Gurutuba é uma das maiores comunidades quilombolas de Minas Gerais. O povo Gorutubano ainda hoje luta por direitos sociais e culturais e enfrenta há anos a usurpação territorial e a ação violenta de fazendeiros. Fonte: https://janauba.mg.gov.br/cidade/historia; http://mapadeconflitos.ensp.fiocruz.br/.
} 
Ciências da Natureza e suas Tecnologias, Ciências Humanas e Sociais Aplicadas), além da Formação Profissional. São oitenta e seis temas que perfazem uma carga horária de três mil horas distribuídas ao longo do curso. Cada Tema Gerador é trabalhado de forma interdisciplinar pelos docentes das diversas áreas do conhecimento;

2. Temas Geradores Essenciais de Integralização: são onze temas geradores Interdisciplinares que integralizam saberes da formação geral e da formação profissional. Esses temas perpassam todo o currículo do curso, com uma carga horária de quatrocentas e quarenta horas a serem cumpridas pelos educandos. A ideia é que, a partir de uma perspectiva interdisciplinar de ensino, caminhemos para uma perspectiva de superação das disciplinas, ou seja, transdisciplinar;

3. Temas Geradores Essenciais de Aprofundamento: são vinte e seis temas divididos entre as quatro grandes áreas do conhecimento e a Formação Técnica Profissional, onde os discentes têm autonomia de traçar seu próprio itinerário formativo, desde que cumprida a carga horária total de duzentas horas. O educando pode aprofundar-se em uma determinada área do conhecimento ou na combinação entre elas. Caso tenha interesse em se aprofundar na área de Ciências Humanas e Sociais Aplicadas, por exemplo, pode cumprir Temas de Aprofundamento nessa área de acordo com a sua disponibilidade de horário livre. Ainda dentro da carga horária de aprofundamento curricular, consideramos a possibilidade de o discente participar de projetos de ensino, pesquisa e extensão, acreditando que tudo é saber, ou seja, tudo contribui para o crescimento escolar, científico, cultural, enfim, humano.

As ementas dos temas geradores não contêm conhecimentos de apenas uma área do saber. Ao contrário, priorizam temáticas que são, em sua maioria, interdisciplinares e transdisciplinares, e contemplam uma gama de saberes que se entrelaçam.

Como síntese de todo conhecimento gerado no decorrer dos cinco períodos trabalhados em cada ano letivo, propõe-se, como trabalho final, a geração de um produto tecnológico pelos discentes. A ideia é que sejam mobilizados todos os conhecimentos adquiridos ao longo dos períodos e, como apanhado de todos esses saberes internalizados, os discentes sejam capazes de contribuir com algum setor da comunidade da área de Vigilância em Saúde em Janaúba ou em outra cidade do Território da Serra Geral, gerando tecnologias 
para melhoria da qualidade de vida das pessoas. Acreditamos que assim podemos levar conhecimento à nossa comunidade, ultrapassar os limites dos muros da nossa instituição e estender os nossos saberes a quem deles mais necessitam.

Essa proposta de integração interdisciplinar, com vistas à transdisciplinaridade, está amparada na práxis freireana, na tese de que é na "ação e reflexão dos homens" (FREIRE, 1987, p. 52) que o mundo pode ser transformado. Nessa perspectiva, temos como concepção o exercício de repensar as estratégias pedagógicas e manter um olhar crítico e reflexivo que nos permita avanços na permanência e êxito de nossos discentes; de uma escola que se comprometa com a formação dos jovens para o enfrentamento dos desafios da contemporaneidade na direção da educação integral e da formação cidadã.

Em uma ação conjunta, ao ponderar essa nova organização curricular, criamos espaços dinâmicos para que o discente seja coautor da sua trilha formativa. Como declarado anteriormente, abrimos caminhos para que em seu horário livre os discentes possam, em sua organização formativa e sempre orientados, fazer aprofundamento de temas de seu interesse e participar de projetos de ensino, pesquisa e extensão. Esses mesmos projetos estão integrados à carga horária do curso, o que possibilita um maior diálogo entre todas as áreas e estratégias formativas.

\section{Sobre o eixo integrador dos conhecimentos}

O eixo integrador dos conhecimentos que compõem a proposta curricular desse curso é: Atenção Integral à Saúde; Trabalho; e Desenvolvimento Social. O eixo foi escolhido pela comunidade escolar como estratégia interdisciplinar e, portanto, integradora, que perpassa e sustenta todo o currículo.

Parte-se do pressuposto de que é preciso que a educação ofertada para um curso na área de saúde se assente na atenção integral à saúde como integradora do currículo que, consequentemente, gerará desenvolvimento social. Para Pinheiro e Mattos (2004), a integralidade é um dos princípios doutrinários da política do Estado brasileiro para a saúde o Sistema Único de Saúde (SUS) -, que se destina a conjugar as ações direcionadas à materialização da saúde como direito e como serviço.

Toma-se também, o conceito de trabalho como eixo integrador do currículo, como práxis humana, ou seja, "uma práxis verdadeira onde os homens superam o estado de objetos, como dominados, e assumem o de sujeitos da história" (FREIRE, 1987, p. 216). 
Por fim, o que se espera de uma educação dessa natureza é que seja emancipatória e que gere desenvolvimento social. Calazans (2014) aponta na mesma direção em que desejamos caminhar. Suas palavras representam o que perseguir quando se trata de pensar em caminhos alternativos para um desenvolvimento que seja verdadeiramente social. Para o autor, qualquer projeto alternativo que não esteja imbuído da construção de um horizonte de transição não funcionará como estratégia de mudança e, dessa perspectiva, a primeira coisa a retomar é a crença de que é possível mudar o estado das coisas nos territórios, mudar o mundo. A nossa utopia é que, pela educação libertadora, essa mudança seja possível.

O currículo do curso assenta-se na ótica do todo e não das partes. Reconhece a existência de diferentes níveis de realidade, o que, segundo Freitas, Morin e Nicolescu (1994), é inerente à atitude transdisciplinar; não separa os conhecimentos artificialmente por disciplinas, aponta na direção de uma outra educação, não mais negligenciada em forma de currículos rígidos e sectarizados.

\section{Considerações finais}

As reflexões aqui propostas visam acolher um trabalho que não é estéril, ao contrário, são reflexões de um trabalho coletivo pautado nos referenciais teórico-conceituais da práxis educativa freireana, que nos confirma que sim, é possível fazermos a aplicação dos conceitos de Freire como ponte para uma realidade educacional transformadora.

Sabemos da amplitude da temática em questão. Reconhecer os nossos limites requer o entendimento de um trabalho que não se encerra por aqui, mas provoca inquietação, própria da dialética que dá sustentação à práxis freireana. É importante enfatizar, como bem nos lembra Paulo Freire em sua Pedagogia da Autonomia, que não há docência sem discência (FREIRE, 1996); assim, também, não há professores autônomos sem pesquisa. Freire nos ensina que faz parte da prática docente a indagação, a busca, a pesquisa e que "não há ensino sem pesquisa e pesquisa sem ensino" (FREIRE, 1996, p. 29). Isso nos faz repensar o papel do professor e sua importância no processo ensino-aprendizagem, afinal de contas, o professor é também um sujeito nesse processo.

A luta de classes é histórica, e cada vez vemos mais a ação da classe dominante em tentar reduzir a ação dos grupos subalternos. É essa a nossa realidade norte-mineira. Nos Cadernos do Cárcere, Gramsci (1975) também já discutia a necessidade de atenção ao desenvolvimento político do conceito de hegemonia e o aprofundamento do conceito entre 
teoria e práxis como forma de compreendermos melhor essas questões para estarmos preparados para o seu enfrentamento, tendo em vista a existência de aparelhos institucionais que são utilizados para consolidar uma agenda política para Educação pautada nos mecanismos de regulação arbitrária, ideologia religiosa tendenciosa e desrespeito às desigualdades.

Sendo assim, calcados na perspectiva da Educação popular, libertadora, emancipatória e verdadeiramente para todos e todas, seguimos redesenhando as nossas práticas pedagógicas por meio de um currículo vivo, buscando outras possibilidades de Educação, com vistas à verdadeira emancipação dos sujeitos. O trabalho proposto pelo IFNMG, Campus Avançado Janaúba, a partir dos temas geradores, materializa a aproximação da realidade com a educação libertadora, na qual o ato de ensinar, como nos ensina Freire (1996), se dá pela rigorosidade metódica, corporeificação das palavras pelo exemplo, consciência do nosso inacabamento e, principalmente, pela amorosidade.

Sabedores da importância da semeadura, lançamos a terra as nossas sementes. Estamos na terceira oferta do curso técnico em Vigilância em Saúde integrado ao Ensino Médio no IFNMG, Campus Avançado Janaúba. O tempo encarregar-se-á de nos trazer os feedbacks que precisamos. A nossa certeza é que, amparados na práxis freireana, em seus sentidos e significados, demos um passo importante no enfrentamento a todas as formas de opressão, dominação e alienação tão características de uma sociedade desigual como a nossa.

O que desejamos é que a nossa escola seja sempre fonte inesgotável de humanidade e que tudo o que dela advenha se apresente como instrumento de ação política junto às massas populares na perspectiva de sua conscientização e emancipação.

\section{Referências}

BRASIL. Base nacional comum curricular. Brasília: Ministério da Educação, 2017. Disponível em: http://basenacionalcomum.mec.gov.br/images/BNCC_EI_EF_110518_versaofinal_site.pdf. Acesso em: 25 nov. 2019.

BRASIL. [Constituição (1988)]. Constituição da República Federativa do Brasil. Brasília, DF: Senado Federal, 1988.

CALAZANS, M. Conflitos socioambientais e resistências: construindo territórios de utopia. In: BARROS, J. ; GUTERRES, A.; SILVA, E. B. (org.). Caderno de Debates 6: Territórios de Utopia: resistências aos impactos dos projetos de desenvolvimento no Brasil. Rio de Janeiro, 2015, p. 85-90. Disponível em: https://fase.org.br/wpcontent/uploads/2015/11/caderno6_web.pdf. Acesso em: 11 ago. 2021. 
COLASANTI, M. A moça tecelã. 13. ed. São Paulo: Global, 2004.

FREIRE, P. Pedagogia da autonomia: saberes necessários à prática educativa. São Paulo: Paz e Terra, 1996.

FREIRE, P. Pedagogia da esperança: um reencontro com a pedagogia do oprimido. Rio de Janeiro: Paz e Terra, 1992.

FREIRE, P. Pedagogia do oprimido. 11. ed. Rio de Janeiro: Paz e Terra, 1987.

FREITAS, L.; MORIN, E.; NICOLESCU, B. Carta da transdisciplinaridade. Convento da Arrábida, Portugal, 6 nov. 1994. Disponível em:

http://cetrans.com.br/assets/docs/CARTA-DA-TRANSDISCIPLINARIDADE1.pdf. Acesso em: 18 ago. 2021.

GRAMSCI, A. Quaderni del carcere. Edizione critica dell'Istituto Gramsci. A cura de Valentino Gerratana. Torino: Giulio Einaudi, 1975.

KONDER, L. O futuro da filosofia da práxis. São Paulo: Expressão Popular, 2018.

KUENZER, A. Z. Exclusão includente e inclusão excludente: a nova forma de dualidade estrutural que objetiva as novas relações entre educação e trabalho. In: SAVIANI, D.; SANFELICE, J. L.; LOMBARDI, J. C. (org.). Capitalismo, trabalho e educação. 3. ed. Campinas: Autores Associados, 2005. p. 77-96.

LOSURDO, D. Hegel, Marx e a ontologia do ser social. Trabalho \& Educação, Belo Horizonte, v. 24, n. 1, p. 117-130, jan./abr. 2015. Disponível em:

https://periodicos.ufmg.br/index.php/trabedu/article/view/9415. Acesso em: 6 jun. 2021.

MANACORDA, M. A. Marx e a pedagogia moderna. São Paulo: Cortez, 1996.

MAPA DE CONFLITOS. Envolvendo injustiça ambiental e saúde no Brasil. Disponível em: http://mapadeconflitos.ensp.fiocruz.br/. Acesso em: 1 maio 2021.

MARX, K. O capital. São Paulo: Civilização Brasileira, 2002.

MARX, K.; ENGELS, F. A ideologia alemã. Tradução de Luís Cláudio de Castro e Costa. São Paulo: Martins Fontes, 2001.

MESQUIDA, P. Paulo Freire e Antonio Gramsci: a filosofia da práxis na ação pedagógica e na educação de educadores. HISTEDBR, Campinas, n. 43, p. 32-41, set. 2011. Doi: 10.20396/rho.v11i43.8639926. Disponível em:

https://periodicos.sbu.unicamp.br/ojs/index.php/histedbr/article/view/8639926. Acesso em: 2 maio 2021.

NOCE, M. A.; FERREIRA NETO, J. A. A população rural do território da Serra Geral Minas Gerais. Camponeses ou agricultores familiares? IDeAS, Rio de Janeiro, v. 9, n. 1, 2015. Disponível em: https://revistaideas.ufrrj.br/ojs/index.php/ideas/article/view/147. Acesso em: 10 jun. 2021. 
PACHECO, E. Os institutos federais: uma revolução na educação profissional e tecnológica. Natal: IFRN, 2010. Disponível em:

https://memoria.ifrn.edu.br/bitstream/handle/1044/1013/Os\%20institutos\%20federais\%20\%20Ebook.pdf?sequence=1. Acesso em: 27 jun. 2018.

PINHEIRO, R.; MATTOS, R. A. de. Construção da integralidade: cotidiano, saberes, práticas em saúde. 3. ed. Rio de Janeiro: Cepesc: IMS: Uerj: Abrasco, 2004.

PREFEITURA DE JANAÚBA. Disponível em: https://janauba.mg.gov.br/cidade/historia. Acesso em: 1 maio 2021.

RAMOS, M. N. Concepção do ensino médio integrado à educação profissional. In: RAMOS, M. N. O ensino médio integrado à educação profissional: concepções e construções a partir da implantação na Rede Pública Estadual do Paraná. Curitiba: SEED, 2007.

RAMOS, M. N. Concepção do ensino médio integrado. Curitiba: SEED, 2008. Disponível em: https://tecnicadmiwj.files.wordpress.com/2008/09/texto-concepcao-do-ensino-mediointegradomarise-ramos1.pdf. Acesso em: 27 jun. 2018.

RAMOS, M. N.; CIAVATTA, M. Ensino médio integrado: concepção e contradições. São Paulo: Cortez, 2005.

SAVIANI, D. Pedagogia: o espaço da educação na universidade. Cadernos de Pesquisa, São Paulo, v. 37, n. 130, p. 99-134, abr. 2007. Doi: 10.1590/S0100-15742007000100006.

Disponível em: http://www.scielo.br/scielo.php?script=sci_arttext\&pid=S0100-

15742007000100006\&lng=en\&nrm=iso. Acesso em: 22 nov. 2019.

SEMERARO, G. Filosofia da práxis e (neo)pragmatismo. Revista Brasileira de Educação, Rio de Janeiro, n. 29, p. 28-40, maio/jun./jul./ago. 2005. Doi: 10.1590/S141324782005000200003. Disponível em: https://www.scielo.br/j/rbedu/a/Cjxrnd9QzJRJdLjrwfMyThk/?lang=pt. Acesso em: 2maio 2021.

VÁSQUEZ, A. S. Filosofia da práxis. Buenos Aires: CLACSO. São Paulo: Expressão Popular, 2011.

Submetido em 29 de junho de 2021. Aprovado em 12 de agosto de 2021. 